\title{
Facial y Fascial
}

\section{Facial and Fascial}

\author{
Alfredo Pinzón-Junca • Bogotá, D.C. (Colombia)
}

Ocasionalmente se cometen errores ortográficos al escribir términos fonéticamente similares, como edema fascial, fascies hipocrática o síndrome miofacial. El conocimiento de la etimología de estas palabras ayuda a entender sus diferencias.

Facial: [inglés: facial] (Del latín medieval faciăl( em) [faci(es) 'cara' + ălem]; documentado en español desde 1400):

1. adj. De la cara o relacionado con ella.

2. adj. Perteneciente o relativo a la cara o el rostro.

Sinónimo: rostral (en desuso).

Facies: [inglés: facies] (Del latín facies 'cara'; pasó al latín medieval y se siguió usando hasta la actualidad en medicina en determinadas expresiones como facies hipocrática):

1. s.f. Aspecto y expresión del rostro motivado por una enfermedad.

2. f. Med. Aspecto del semblante que revela alguna alteración del organismo.

Sinónimo: cara, máscara.

Fascial: [inglés: fascial]

1. adj. De la fascia o relacionado con ella.

Sinónimo: aponeurótico.

Fascia: [inglés: fascia] (Del latín fascia 'banda que ata', 'faja', 'venda'; reintroducido y documentado como término anatómico con el significado actual desde 1788):

1. s.f. Vaina de tejido conjuntivo fibroso que recubre una víscera, un músculo esquelético o un grupo muscular.

2. f. Anat. Membrana fibrosa que recubre los músculos.

Sinónimo: aponeurosis.

La diferencia en la grafía es sutil al escribir con " c" o con "sc", pero el significado es diferente, ya que se refiere a la cara en el primer caso, y a la aponeurosis en el segundo. A continuación algunos ejemplos de la correcta escritura de estos vocablos:

$\checkmark$ facies leonina, facies de luna llena, facies agónica, nervio facial, arteria facial, parálisis facial.

$\checkmark$ fascia muscular, fascia plantar, fascia palmar, miofascial,fascia lata.

\section{Fuentes}

Diccionario de la Real Academia Española de la Lengua, disponible en: www.rae.es

Real Academia Nacional de Medicina. Diccionario de Términos Médicos. Editorial Médica Panamericana. 2012

* Envíe sus inquietudes, sugerencias o comentarios a: contacto@actamedicacolombiana.com - alfpin@ hotmail.com

Dr. Alfredo Pinzón-Junca: Especialista en Medicina Interna y Psicoanálisis. Hospital Universitario de La Samaritana y Hospital Simón

Bolívar. Coordinador del Consejo de Acreditación y Recertificación de la ACMI ${ }^{\circledast}$. Bogotá, D.C. (Colombia).

E-mail: alfpin@hotmail.com

Recibido: 18/IX/2018 Aceptado: 20/IX/2018 